\title{
Veblen 2.0: Neoliberal Games of Social Capital and the At- tention Economy as Conspicuous Consumption
}

\author{
Kane X. Faucher \\ Faculty of Information and Media Studies, Western University, London, Canada, \\ kfauche@uwo.ca
}

\begin{abstract}
The purpose of this article will be in reading acts of prosumer behaviour in social networking environments through a Veblenian lens, supported in part by the post-Marxist insights of Guy Debord, especially with respect to the issue of celebrity emulation, conspicuous leisure as constructed by the labour of profile management and promiscuous online interactivity, and acts of status enhancement or aggrandizement. Such a discussion must be set in the current context of the normative frame of neoliberal ideology which champions the values of the entrepreneurial self, devolved competitiveness as a form of - in this case social rather than strictly economic - neo-Darwinism, and the touted virtues of speed and connectivity. Ultimately, it is our hope to link these conspicuous online practices to the ideological framework to demonstrate how prosumption plays an integral role in the quantification of the social economy as expressed as "social capital". In order to achieve these objectives, strict and operational definitions of prosumption, conspicuity in the Veblenian literature, and neoliberalism will be required. The line between social and economic capital is not a definitive one, and that the behaviours and motives associated with increasing social capital may be weighted more to the individual and influenced by neoliberal values that recode the social as derivative of the economic.
\end{abstract}

Keywords: Conspicuous Consumption, Prosumption, Status, Spectacle, Facebook, Veblen, Neoliberalism, ICTs, SNSs

\section{Ideological Ghost in the Machine}

The imbrication of neoliberalism and information communication technologies (ICTs) is an arrangement of mutual advantage whereby both function as instruments that increase speed, reach, and power over global distances. Emerging out of the popularization of ICTs has been the touted advantages of social connectivity that compress space and time, this compression allowing for just-in-time production and consumption that cuts across products, services, and social interaction. Inasmuch as neoliberalism can make ICTs its exclusive instrument, this is not to say that there are not other ideological structures that do not also prosper from the inherent advantages presented by these technologies, nor can an absolute claim be made with any validity that social networking sites (SNSs) are without the potential for developing or sustaining acts dedicated to social welfare and the public good. At best, we might say that the implications of software design, the heavily commercialized spaces of SNSs appear to favour a more capitalist, anglocentric, and specifically neoliberal agenda. The heavy preponderance of capitalism-enabling instruments, be this the use of OpenGraph or other means to "hijack" social interaction as a patented means to enhance micro- and targeted advertising, underscore the ideological bias, and anneal the presence of said bias in what is possible in social interaction online.

We must make clear that the focus here on online social goods of conspicuous production and consumption do not take into consideration those that may be considered in-app or onsite purchasing in virtual worlds such as Second Life. We are here restricting ourselves to the social behaviours that are geared toward increasing social capital and claiming stake in the attention economy. Moreover, we may come to question whether the terms of prosumer or produser are sufficient to replace the producer-consumer distinction, even when considering user-led collaborative processes for content creation. Contrary to Bruns $(2008,2009)$, production and consumption may still be useful and operative terms. If we were, for example, to 
turn to pre-Internet media, a reader who submits a letter to the editor of a newspaper, or a listener who participates in a radio call-in show, could theoretically be classed under prosumption. However, the functions of production and consumption are still clear and distinct. The fanfare associated with the benefits of prosumption (Ritzer and Jurgenson 2010) and produsage (Bruns 2008) are said to inform a radical shift in economic models (Benkler 2006), while possibly overlooking the predatory and exploitative aspects of freely created and distributed content (Fuchs 2010).

The alliance between the emergence and rapid proliferation of ICTs and neoliberal ideology has already been recognized by several authors (Castells 1996; Dyer-Witheford 1999; Harvey 2005; Bulut et al 2009; Neubauer 2011). The specific context in which the digital social environments may find themselves may have adopted in part some of the shibboleths of informational capitalism insofar as it represents a "dialectic between forces and relations of production and consumption (that) revolves around technologies specifically designed (and marketed) to enhance, capture, transmit, and store human capacities such as creativity, communication, co-operation, and cognition" (Manzerolle 2014, 206). This form of capture may go under different names, be it Debord's notion of spectacle or Lieven de Cauter's "capsularization". Under these conditions, production itself is transformed, and social "prosumption" in the online environment comes ever more to resemble competitive business: "It's a capitalism no longer directed toward production but toward products, that is, toward sales and markets" (Deleuze 1995, 181). The values of neoliberalism, insofar as they have migrated into the social realm as an all-pervasive value system no longer restricted to governance and economy, may be said to "haunt" even online social environments wherein one might hear the echo of the values of rational action and instrumental individualism.

\section{The Gospel of Social Capital(ism)}

Just as Veblen tells us that the study of economics should not be bracketed away from broader social influences, it also holds that the study of social relations should not dismiss the influence of economic ideas. The invocation of the term social capital requires critical examination especially given its popular usage and lack of definitional consensus. Labonte (2008) contests that social capital does not actually exist, but is perceived differently pending ideological standpoint. For the neoliberal advocate, social capital is one of a variety of means to increase economic growth, whereas those who are advocates of social justice, social capital is seen as a form of community empowerment. Bourdieu and Wacquant define it as "the sum of the resources, actual or virtual, that accrue to an individual or group by virtue of possessing a durable network of more or less institutionalized relationships of mutual acquaintance and recognition $(1992,14)$. Although sociology has long held some view of social capital under different names, Bourdieu is to be credited with its most sustained formalization and its comparison, if not reductive quality, to capitalism. Whereas human capital is individually based, and economic capital is a measure of wealth, social capital is found in, and generated by, social relations. In this way, unlike economic capital, social capital is considered an intangible asset. This has not prevented others from attempting to demonstrate how social capital has measurable impact on economic performance (Knack and Keefer 1997).

In the simplest of terms, social capital is derived from community engagement and the trust-bonds that form in that community that can be leveraged for personal and public benefit. In all such cases, actors in a community must engage in a process of resource management, which entails a knowledge of what resources are at hand, and how to leverage these for some goal or cluster of goals. In the online context, social capital is frequently touted as a pathway for creating measurable change. However, not all see social capital as increasing as a result of online activity (Putnam 2000). A promiscuous connectivity can be said to be a necessary but not sufficient condition for increasing social capital, for the essential component would involve some goal-directed behaviour, consensus, and resource management through acts of collaborative development and strategic allocation. The plain fact that the resources must be managed attests to either the finitude of social capital, that it is not an 
economy based on superabundance, or that it must be strategically directed to achieve a goal or set of goals that produce advantage to actors in a community.

In the above terms, social capital is effectively a synonym for "people power", but it is unclear what direct connection it may have with capital itself beyond a subjective benefit derived from acts of mutual activity. The "capital" aspect of social capital remains somewhat nebulous as there seems no clear means of computing the actual capital gains or losses from various community acts, and that any capital gained does not result in a stable exchange value. That is, there is no "currency" whereby investment in a social and community action can be reinvested in an entirely disparate action. If the social capital is associated with a community raising awareness over a controversial pipeline, said capital cannot be invested or leveraged for actively supporting the development of a video game that has nothing to do with environmental protections, or the proceeds therefrom not flowing to some environmental concern. Although it is possible to reinvest social capital in peripherals that support the central objective in some way, or are associated with that objective ideologically or epistemologically, there is not a universal currency, and nor is it technically measurable.

If we view many of the actions on Facebook as a form of building some form of capital whereby an investment in the digital self has the purpose of increasing one's social standing, there are "measures" associated with this, even though they do not lend themselves to something stable in terms of transferability and exchange. The capitalizing of the digital representation of the self, for example, is a status-increasing initiative that is linked to social capital as it requires a community to confer a value on the individual seeking to increase his or her own social capital. One would, most likely, seek to conspicuously increase said status by optimizing one's profile details and by what one chooses to post. As Walther (1996) has shown, impression formation is much easier with respect to idealized self-representation online than in offline contexts. Although Walther cites anonymity and asynchronicity as factors in the facility of developing favourable impressions these environments, we might also add the aspect of control unique to these environments in terms of profile management.

Following Putnam's distinction between bridging and bonding social capital $(2000)^{1}$, Ellison et al's study found "a robust connection between Facebook usage and indicators of social capital, especially of the bridging type. Internet use alone did not predict social capital accumulation, but intensive use of Facebook did" $(2008,1167)$. Although the finer-grain tactics involved in increasing popularity are outside the scope of this article, the vast literature on the subject on Facebook and popularity has included attractiveness of profile picture, the similarity of other friends connected to the user, and inferred cues from acts of extraversion (Utz 2010).

Within a very particular and neoliberal frame, "social capital" and "attention economy" privilege the second word in these concepts at the expense of the first as the means by which economic growth can occur, generally by producing "educated subjects" who may engage in entrepreneurial activities or collaborative schemes in the service of economic growth.

In assessing the motivations that give rise to the development of social capital, off- or online, Portes (1998) identifies these as either consummatory or instrumental; consummatory insofar as they reflect deeply embedded social norms, and instrumental insofar as they involve the more economic aspects of rational action theory by which individuals perform actions with a view to gain advantage or profit. It might be considered more common that those engaged in the exercise of increasing social capital do so for instrumental reasons and thus for their own benefit (De Graaf and Flap 1988; Burt 1992). Rational action and rational choice theory are in themselves essential components to the economic theories that underpin neoliberalism, mostly espoused by the Austrian School and later Chicago School of economics. Emblematic of this view are the axiomatic foundations of praxeology that assume in advance that all human action is rational (von Mises 1963, 18-21), and so it follows from this that the function of choice in the individual seeks at the outset an advantage on the basis of a rational calculation. These economic views of the human being's role as a calculative agent would

\footnotetext{
${ }^{1}$ Bridging social capital may be characterized as simply being connected to someone else, akin to Granovetter's theory of the benefit of weak ties. Bonding capital is a much more intimate relation between two users.
} 
eventually lead economists of this stripe to make recommendations for government policy that called for just enough state intervention to dismantle government control over the markets, allow said markets to regulate themselves, and to provide incentives for empowering the citizen as a rational and informed consumer within the framework of liberty. This focus on the rational individual as opposed to cooperative social groups that had traditionally been a source of support if not also significant improvements in working life if we think of trade unions, had been instrumental to privileging the individual over the collective. The writings of those such as Friedrich von Hayek and later Milton Friedman, were carefully studied and implemented in the US as early as 1971 when then-President Richard Nixon shifted the US economy from the gold standard to one of floating currency. These economic views were seen by their advocates as the way out of financial crises that arose during the 1970s such as the oil shortage and the near bankruptcy of New York City. With these new economic principles in place, an alliance between these views and a minority of evangelical Christians who espoused "family values" gave rise to the populist movements that brought to office the official mouthpieces of the neoliberal-neoconservative hybrid: Ronald Reagan, Margaret Thatcher, and Brian Mulroney. The steady deregulation of markets under the charge of free market fundamentalism spurred unprecedented wealth production temporarily, but the speculative bubble popped which led to recession. The fundamental idea that deregulated markets, aided by computing and the (mis)application of mathematical models, would be relatively stable because those participating in the speculation were seeking their own selfinterest which - in a very selective reading of Adam Smith - would guarantee a good for all created ever more instabilities and concentration of wealth in fewer hands. Despite the claims of some decorated economists that markets could be predicted, a fundamental failure to appreciate the irrationality of human beings as speculators and a hasty misapplication of mathematical models resulted in a series of unpredictable oscillations in the market from the recession of the 1990s, the IT boom and bust of 2001, and the more recent global downturn of 2008.

If large financial markets are too complex if not chaotic, their oscillations privy to allegedly rational actors making rational choices, we might ask if the same criticism applies to the social market and to the development of social capital. It would stand to reason that if human instrumentality as a motivation for behaviour in making choices to leverage social capital for individual gain can be viewed in Veblenian terms as infused with the broader sociological conditions of conspicuous consumption as an evolutionarily cultural invariant from the time of predatory cultures to the modern day, this in itself might serve as an indictment against the over-optimistic assumptions related to social capital.

\section{Veblen on Facebook}

In Veblen's technical terminology, the features of Facebook's environment may attest to an evaluative apparatus of the invidious by which others may be compared according to quantifiable measure. How many "likes," or "friends" online may, in fact, be a function of reducing the subjective qualities of "social" and "attention" to numerical considerations alone as a measure of popularity. Mapping free market principles unto social activity becomes the norm in many digital environments, and so the qualitative value is subordinate to the quantitative, more easily apprehended by a digital audience in the assigning of value - especially with the ease of approbation markers such as the "thumbs-up" or the tail of posted content by a series of threaded comments that demonstrate apparent proof of attention. Ultimately, it is the search for status enhancement through a conspicuously "economic" means as the "royal road" to self-actualization. It is, for Veblen, the desire for status that is the driving force in scaling production beyond that of simply satisfying basic needs.

Just as Veblen argues, those who seek status must seek ways of providing a demonstration of their pecuniary strength, generally through acts of wasteful consumption and unproductive use of time, the same might be said with respect to the online social venues whereby it is not explicitly material wealth that is being generated and displayed for status enhancement, but a particularly social variety that is also measured in much the same manner as ma- 
terial wealth. We say not explicitly material wealth here for the reason that there are indirect or inferred displays of material wealth, be this in being able to afford the devices to access these social venues, or more evidently through posted pictures on a user's profile where they can be seen traveling to expensive destinations or purchasing and enjoying products associated with a particular class.

At the heart of egocentric or instrumentalist social capital is the drive toward accumulation strategies. In search of "virtual" goods as a marker of social class, actions directed to accumulation and conversion lead steadily to becoming the "accepted badge of efficiency" whereby the "possession of goods, whether acquired aggressively by one's own exertion or passively by transmission through inheritance from others, becomes a conventional basis of reputability" (Veblen 2010, 19). We must here make a few distinctions for clarity: in the first, accumulation should not be thought in strictly material terms, nor the "goods" that are trafficked on SNSs. Instead, accumulation takes on an objectivizing approach to the myriad subjects who are subscribers to the SNSs in that they can be accumulated as a sum of connections that further enhance the perceived status of the central "node" (in a social network, each node is central to itself as an egocentric access point). Moreover, social approbation markers on sites such as Facebook, making the "thumbs-up" icon linked to a quantity, constructs the appearance of value of the posted content of a user on the basis of numerical "likes". On Facebook, "friends" and "likes" - both of which in non-economic terms represent affinity and approbation - become standardized as a measure of social wealth: the more likes and connections, the higher the perceived value of the user ${ }^{2}$. And so, "the end sought by accumulation is to rank high in comparison with the rest of the community in point of pecuniary strength" (Veblen 2010, 20). In this case, the competitive nature of said environments is not linked to pecuniarily based wealth, but according to the premium attributed to quantifiable social wealth. The scene of competition among peers and those who may be privy to the online actions of Facebook users outside the subgroup can be measured in terms of an attention economy: value indexed on the quantitative views of posted content, approbation cues such as "likes", and social mention, all of which should ideally be upwardly trending and "occupy" the finite resource of network users' attention.

As popularity can be considered within a competitive frame, studies on Facebook have determined that number of friends and length of the "wall" feature are factors in judging popularity (White 2005). We may question if these studies may apply in larger samples with respect to higher numbers of connections, for it is possible to add connections indiscriminately just to inflate the number, or that even with a higher number of connections, a paucity of interactions would suggest a lack of popularity.

Although digital environments appear to conform to an economy of abundance on account of ease in duplication of immaterial goods trafficked online as endemic to the nature of digital information flows, both the acquisition of meaningful social capital and the attention economy are still indexed on an economy of scarcity, and hence the requirement for competition to secure said scarce resources. Nor is it established that any gains in social capital will retain their value over time. Acquiring 1,000 "likes" on a Facebook post will unlikely retain its value, although it may retain some of its value in subsequent posts or in the promotion of said subsequent posts according to the algorithm that determines relevance on the basis of popularity, generally measured in terms of impressions and interactions as past precedent. However, like Amazon.com's book rank algorithm, rank decay sets in quickly, and so new stimulus is required to increase social capital. This can be achieved through frequently posted content that will enjoy approval from the social group, as well as by growing the network overall. Although a larger network may increase the probability of acquiring more capital, it may also trend in the reverse if the supply of posted content by the additional users exceeds available attention.

In addition, there is no stronger indictment against the optimism associated with social capital than the phenomenon known as slacktivism or clicktivism where millions of users can click a button in support of a protest, but that is where their duties of social conscience end.

\footnotetext{
${ }^{2}$ Potentially speaking; there are numerous exceptions where this may not be the case.
} 
To click a button in signing a petition does not always lead to further action, but it appeases the conscience of the user in much the same way that residents in a city with a recycling program may feel entitled to calling themselves environmentalists simply because they sorted their recyclables and placed them on the curb for collection ${ }^{3}$.

The comparative and competitive drive among users may be technically defined, pace Veblen, as invidious insofar as the grading or rating of others is based on relative worth or value. (Veblen 2010, 22). This invidiousness pervades SNSs as part of the evaluative framework by which others may be said to be judged, against a measure of peculiar markers that are largely quantitative in nature. Such a competitive environment, populated in part by social profiteers, aligns with the values of entrepreneurialism and its ideological champion, neoliberalism. The large proportion of actions on Facebook, apart from mutual or participatory surveillance of connections, involves self-promotional content or actions that attempt to attract attention to the user. The values of arch-individualism interwoven with the ideological tissue of neoliberalism focuses on personal potential as something developmentally infinite, and that self-reliance is preferred over more communitarian values of cooperation and interdependence. Online, the digital self becomes commodified as a product on the open market of SNSs, and the software architecture of Facebook and its user-interface appears to enable if not encourage such behaviours.

Social wealth, earned or inherited by association with reputable or popular persons, is not yet social capital. In the games of online social capital, social wealth must be first transferred to the digital milieu in some measurable way whereby said wealth can be leverage for producing capital. In other words, the truly social and qualitative must be transubstantiated as something quantitative that reduces or effaces the subjectively social. As the socially rich offline may have a higher probability of being socially rich online according to Social Enhancement Theory (Merton 1968), this transfer or exchange may prove of some facility to those who already enjoy a large number of social connections in the offline world. These must be reiterated and formalized in the online milieu by way of invitations to connect, thus mapping offline social wealth unto the online as evidence of social wealth in that milieu. One of the unique aspects of the online milieu of SNSs is that social connections become, pending privacy settings, visible to a spectator audience, perhaps in a similar way as Society Pages in the past detailed the lives and gossip circulating about members of the upper classes. There are, however, ways of "gaming the system" to increase the number of connections a user has such as sending out invitations to others the user does not know in an entirely indiscriminate fashion solely for the purposes of inflating quantity of connections and thus perceived popularity. With respect to users who have a product or service, Facebook allows for the creation of dedicated pages for their promotion. In such cases, the user can opt to develop a following organically, or purchase services that artificially increase the number of likes and followers. Fivver.com, for example, hosts several users that offer such services for a fee.

Social wealth may be seen as intrinsic use value, whereas its mediatization and commodification in online social networks gives it a new status as exchange value in the form of social capital. What is being traded and gained, generally at a perceived profit, is the commodity form of the digital self and its associated productions. Investment occurs through conspicuous production, and later management, of the personal profile. This "property" of the user, which is in effect subject to the rent paid to the host such as Facebook in non-monetary forms, is a trading area where is housed all the "goods" of the user. These goods may take the simple form of preferred tastes in music or film. Or, it may also be the images that asso-

\footnotetext{
${ }^{3}$ A second criticism of social capitalism in SNSs can be attributed to the Arab Spring, but for a different reason. Much of the popular press coverage of the uprisings in Egypt and Tunisia focused on how the people were relying on SNSs to mobilize and organize their political movements without paying any consideration to the non-SNS forms of social communication that were already well established. By weighting the coverage on the value of SNSs for political change, there may be a distinct cultural chauvinism insofar as Western media leveraged or even creatively revised its reportage to sing the praises of a predominantly Western technology as being the catalyst for liberation. In reality, despite the use of SNSs to facilitate political change, this was a supplementary form of communication and not always reliable as some regimes already had surveillance systems in place to monitor online activity for easy identification and capture of dissidents, or otherwise blocked access entirely.
} 
ciate the user with some popular product, or a marker of affluence and the means of disposable income in the form of travel pictures to Europe or a sunny resort. One of the distinct advantages of environments such as Facebook is in the way said environments are structured: the media-rich qualities and specific arrangement of the site with a strongly visual bias encourages acts of visual display. Such displays are ideal for meeting the real purpose of conspicuous consumption: to be seen and judged as being of higher status and thus worthy of more attention. All the while, the tireless algorithm in the background harvests keywords for the express purpose of monetizing social interaction.

Friends and visitors who are alerted to a user's posted content can affect that user's social marginal utility value by clicking on the "like" button or supplying a comment. Said friends and visitors may be said to be consumers of the image produced by the user, but are presented with a means for an instant polling. Although Baudrillard, following McLuhan, tells us that contemporary media presents objects as a form of test that minimizes our contemplative time in order to prompt us to respond with a yes or no (Baudrillard 1993,63), so too is the producer also participating in the selective test of producing just the right content that will gain the approval of the audience. Such a production may be judged a failure if it does not provoke a response that is made public; i.e., a "like" or a comment. The production may be judged subpar if it fails to reach a certain numerical threshold such as number of "likes" or comments. If the user seeks to maximize on their return on investment for the productionevent, a certain understanding of what is considered appealing to the social network audience is required. However, this is little more than the necessary but not sufficient condition for increasing social profit; other factors play a role in determining how the "market" responds to the posted content, such as number of connections the "produser" has, and how well advertised the event happens to be according to the proprietary algorithm of the SNS. This suggests that despite what efforts are made by the "produser" to generate and disseminate content that might appeal to an audience, there are a variety of factors outside of his or her control that may have an appreciable effect on social profit. From the standpoint of the produser, given a desire to avoid being in the "Iong tail" of the attention economy (Anderson, 2004), a certain labour is required that aligns with variables of relevance and regularity of posted content to avoid one's production falling below the proverbial fold.

Maximizing on social profit in an environment where one's everyday life is relatively unknown by the connected members of one's network requires developing strategies for making it known by attracting attention to it. Veblen remarks that social situations with a higher number of participants requires tactics for increasing the visibility of conspicuous consumption $(2010,49)$. Such social arrangements with larger numbers of participants who, ostensibly, are also vying for recognition of status among transitory observers increases the probability and intensity of competition.

One may argue that it costs little or nothing to join Facebook, at least once the devices to access it are available to the user. If the "price" of inclusion to Facebook is not overpriced and expensive, then it may seem odd to marshal Veblen's concept of conspicuous consumption to the practices of users on Facebook. However, the price to be paid in using Facebook may include a variety of less tangible costs such as giving Facebook permission to use one's data, as well as time computed as a cost in the use of Facebook. In some ways, using Facebook can be an extravagant use of personal time, and thus may be classed as a form of conspicuous consumption. Veblen makes the critical distinction that use and consumption differs from ownership, just as indolence is not a measure of leisure (Veblen 2010, 16). It is in this way that we might assess some of the issues pertaining to the production of content in terms of ownership, as well as the uneasy relationship of Facebook use as either labour or leisure activity.

The user's Facebook profile is the immaterial product of the user's labour. As such, it enters into an online social commodities market in a competition for attention and an increase in personal social capital. The new technosocial reality of SNSs emulate as far as may be feasible market logics and redefine users as micro-capitalists of the self. This occurs within a unified social economy that is global, out of which a new and virtualized form of wealth can be produced through strategic social partnerships online. Such labour, despite occurring in a 
space dedicated to entertainment and socializing, may be intensive when all factors that go into the production of the digital self and personal social capital are considered, such as posting new content on a regular basis, profile management, and engaging in offline activities that will have value when posted online. This emulation of marketizing practices writ in social terms agrees with the neoliberal understanding of the citizen as consumer, and allows for the creation of a space wherein the "prosumers" of Facebook can enjoy freedoms not experienced in the offline world:

Consumer freedom was originally a compensation for the loss of the freedom and autonomy of the producer. Having been evicted from production and communal self-rule, the individual drive to self-assertion found its outlet in the market game. One can suppose that at least in part the continuing popularity of the market game derives from its virtual monopoly as the vehicle of self-construction and individual autonomy. The less freedom exists in the other spheres of life, the stronger is the popular pressure on the further extension of consumer freedom whatever its cost. (Bauman 1988, 95)

The neoliberal ideology with its aims of globally deregulated trade, flexible accumulation strategies, and promotion of the arch-individual becomes the new bedrock of online social relations. Economic concerns become the spectacular enclosure and teleological purpose of social relations in a rapid feedback-based environment governed by neo-Darwinian survivalism. The highest values of this environment become competition and connection, all of which can be quantified and conspicuously displayed on one's profile. Neoliberalism operates by adopting a "strong" paternalistic discourse that attempts to naturalize economic Darwinism (Peck and Tickell 2002). This means that all labour relations succumb to a discourse of competition that is global in scale. This is aided in part by the precedent set by network discourse assumptions and variants of systems theory such as the first incarnation of ecology whereby Darwin's theories are first generalized, and then freely applied to situations that distend their initial area of application.

We might inquire into the intrinsic value of "likes" and "friends" if these were not visible for public display, and only made visible to the user. It is perhaps for this reason that this may be considered an expression of conspicuity, for the display of such metrics may play a role in proving one's status and value. Such displayed metrics also may lead to "herding" (Huang and Chen, 2006) whereby a higher number of likes not only increases the chances of the content being seen by a larger number of users, but it may also increase the chance that a user will comply by adding their own like. In some respects, the motivation for increasing one's likes resembles that of video games where the goal is to achieve the highest score.

It should be noted that the means to access these networks may in themselves speak to the devolution of the cachet item of leisure to the range of near-affordability by the petty household economy. In this way we may include the devices themselves that are marketed as "aesthetic utility"; that is, any of the devices by Apple's i-range of products, or Google's Android and other peripherals, are specifically designed to be objects that appeal to aesthetic taste, and this "technopulence" mitigated by claims to their utility and necessity. The production - and subsequent disposal at the end of the device's life cycle - is the fruit of working conditions in developing nations that in many respects is substandard in terms of subsistence. The patent truism in Marx holds that the more luxurious the product, the less likely it is that those who manufacture it will be able to afford it. What is to be retained here is the emulative process of consuming apparent luxury goods that also appeal to the conscience of the consumer as something useful and necessary, for a purely aestheticized gadgetry with no obvious utility might not result in popular adoption and thus brisk sales to justify the rapid and enormous requirements of the production and consumption cycle. Where the conspicuousness of the device is on its own not enough to convince consumers to adopt it, other means are invented by which certain features unique to the device come pre-loaded and embedded with proprietary software that cannot be ported to a competitor device. 
In a time of increasing economic austerity with its knock-on effects for a steadily shrinking middle class, it might be reasonable to assume that conspicuous consumption must be seen in terms of scalar adjustments that take into consideration depressed or stagnant wages and available credit (itself arguably the "supplement" of or "replacement" for what would be adjustments to cost of living increases in salary, but may be seen as an abdication by major employers to compensate what they might view as rent-seeking behaviour). As discretionary consumer purchasing power in North America has softened (despite a modest increase in the consumer price index since the 2008 downturn), thus having a deleterious impact on profit, consumption practices might be seen to shift or migrate just slightly to a virtualized form, and this through consumption and production activities in the online social milieu.

Michael Hardt and Antonio Negri signal that, at the heart of network culture is the possibility for greater collaboration among a multitude that might subvert the aims of postmodern capital:

Cooperation is completely immanent to the laboring activity itself. This fact calls into question the old notion (common to classical and Marxian political economics) by which labour power is conceived as "variable capital", that is, a force that is activated and made coherent only by capital, because the cooperative powers of labor power (particularly immaterial labor power) afford labor the possibility of valorising itself. Brains and bodies still need others to produce value, but the others they need are not necessarily provided by capital and its capacities to orchestrate production. Today productivity, wealth, and the creation of social surpluses take the form of cooperative interactivity through linguistic, communicational, and affective networks. In the expression of its own creative energies, immaterial labor thus seems to provide the potential for a kind of spontaneous and elementary communism (Hardt and Negri 2000, 294).

The competition to increase social capital in an attention economy is precisely what grants the online social self-servicing mechanisms their justification and coherence. It does not occur in a space or milieu outside of a corporately controlled environment, and even the notion of a "gift economy" of social reciprocity online is effectively hijacked by a numerical system that assigns extrinsic value to the immaterial labour performed online. There is still a "wage" system in the form of likes and other approbation cues that digitally reify "social" value as something quantifiable. The very plain fact that these social relations which define capital occur on networks that have a material basis at least in terms of requiring cheap manufacturing labour to produce the hardware and precarious labour for the motley services that are created by these hardware may undercut part of Hardt and Negri's argument. But, just as importantly, the online social relations on SNSs are still patterned or defined according to accumulation and competitive strategies whereby each user attempting to secure their "share" of the attention economy must make personal calculations of temporal investment, and that any collaboration or sharing will somehow improve the individual user's online social capital, thus consigning acts of sharing to something entirely extrinsic. While a vast number of online users are engaged in a global competitive practice of accumulating social capital, the reality is that such "accumulation requires commitment from many people, although few have any real chances of making a substantial profit" (Boltanski and Chiapello 2006, 163). In other words, the "winners" in the games of social capital exist at the expense of a multitude of "losers."

Although many users may be engaged in the competitive games by which they can obtain a larger share of attention, this is not always necessarily linked to a concrete purpose. That is, setting aside those who have a specific promotional agenda to market a product or service they are selling, the question of what a user hopes to gain in achieving an arbitrary high number of likes, comments, or connections remains somewhat mysterious. We might speculate that the higher the number of interactive events such as likes or comments, the more the satisfaction in terms of social validation. It is in a return to Veblen that we discover that the motivations are, in fact, deliberate, and although their purposes may vary in their particulars, the end goal is to be accorded by a community with a validated status. Veblen's analysis tells 
us that the drive or imperative for conspicuous consumption, either of goods or time and effort, is contingent upon the size of the audience to be impressed. The more dense the social network, the higher the probability of fierce competition. It is Veblen's intention to view such behaviours as Darwinism writ socially. It is precisely this form of social (and economic) Darwinism supported by neoliberalism (Peck and Tickell 2002) that values competition over collaboration or compassion.

It is here that Facebook as a site of conspicuous prosumption may differ only slightly from Veblen's notion of conspicuous consumption. In the latter, what one consumes becomes a sign of one's purchasing power. In terms of Facebook and the prosumption model, the signs of social approbation in high numbers becomes a sign of one's social power. Pecuniary and social power should not be considered altogether distinct, for at the level of proving one's social power, this comes about through a specific purchase of the time required to develop one's online social prowess through labour. Time spent on Facebook is time not spent in productive wage labour or in other forms of leisure. In this way, the time is "purchased" from these other areas of activity. One might raise two objections here: 1) the integration or interference of SNS activity in our daily affairs of work and leisure suggest that we are comfortably multitasking, and 2) this does not speak to those whose employment may be in the field of social media strategy that requires spending time on Facebook as part of that employment, and thus is not time purchased from work. To the first objection, the interruptions or integration of Facebook while at work or play requires attention to be at least temporarily diverted from those situations in order to attend to Facebook. Moreover, one may question the quality of the user's attention to work or non-Facebook social activities if they are effectively task-switching. To the second objection, the employee whose job it is to oversee a company's social media communications may be technically on Facebook, but for the distinct purpose of promoting the company and not the individual, and this may be a comparable instance to those who are technically at a bar or pub, but who are working in the role of bartender or server.

Social power, no matter how the SNS provides tools for its apparent measurement in terms of likes, does not lend itself to precise measurement at all. There is no formula by which $\mathrm{x}$ number of "like-units" will produce a value that is anything but arbitrary and relative. One can measure power in terms of joules per second as watts, but social power cannot be reduced to standardized measurement. At best, the subjective notion of power - be this political, social, military, or economic - is a form of potestas, and can only be measured according to the relative values of more or less. With respect to social power on Facebook, there is no guarantee that a million likes on a post grants to the creator a special social power. Nor does having 5,000 connections necessarily mean that the user has more social capital at his or her disposal.

It might be said that there are implicit social norms on Facebook, and a gradual building of cultural capital that guides notions of taste, but also which guide to some degree what are the appropriate mechanisms by which to develop social capital specific to Facebook's environment. Already, Facebook's software design restricts certain choices and behaviours. For example, rejected friend requests do not result in the requester being notified of the rejection, and the ubiquitous thumb-icon denoting "like" is the only option beyond taking no action at all (i.e., there is no "dislike") button. These are intentionally designed elements to promote a positive social space that reduces the possibility of hostility and rejection, even if a determined user can find other ways of indulging in antisocial behaviour such as trolling.

\section{Wasting Time}

The surplus production of goods beyond the necessities of life are absorbed by those who crave an increase in status, and thus can be considered the driver in the desire for economic growth, even if it may be considered derivative: "The utility of consumption as an evidence of wealth is to be classed as a derivative growth" (Veblen 2010, 40). For Bataille, there comes a point where the inputs of energy, described as wealth, surpass the requirements of a system or organism to grow and so is kept in a growing inutile reserve that needs to be expended 
(Bataille 1991, 21). If this energy or wealth is not squandered, this may lead to ruination as a result of an enormously building pressure. Although Bataille admits that growth cannot be indefinite, he pegs ostentatious squandering of wealth as the condition of sovereignty. The wealth must be discharged in some way for the "health" of the general economic system. It should be noted that Bataille had written The Accursed Share during the postwar economic boom, in a world polarized by the Cold War, and in the general improvement of overall wages and standard of living, and so the conclusions he arrives at may not be as applicable in a time of extreme wealth concentration, neoliberal-backed austerity, and an exhaustion of the earth's natural resources in a mounting global eco-crisis.

It is, instead, to Veblen's credit that waste has a functional utility, albeit of a secondary value in the way it is leveraged to satisfy a human desire for status. Veblen, committed as he was to applying the gains of Darwinism to the field of institutional practices, largely saw acts of conspicuous consumption by a wealthy elite and leisure class - as well as those of the lower classes partaking of said behaviours as far as their means allowed, in emulation of the upper classes - as an evolutionary invariant; that is, the desire for status by material demonstration of wealth and its wasteful expenditure has only changed in its particulars while the general aspect has remained the same since the beginning of human civilization. The reliance on some form of ceremonial and ritualistic component of wealth display and expenditure for status enhancement can still be seen, says Veblen, in the practices of latter-day institutions.

Veblen's definition of waste is, unlike Bataille's argument for an almost cathartic discharge of excess wealth, that which "does not serve human life or human well-being on the whole." (Veblen 2010,55) Although certain acts and expenditures may be viewed as having at least some value to the individual's well-being and satisfaction, when it solely based on the relative utility of the individual, then it might be deemed wasteful. Moreover, if the act or expenditure is solely to live up to an arbitrary standard set by one's class, as a means to compete with others, we might also class these as wasteful.

If there is an apparent preponderance of adolescents and college students posting pictures of themselves in acts of intoxication and hyperactive socializing, this attests to the display of unproductive time and leisure which marks conspicuous consumption. If online social interactivity can be considered a form of over-indulgent vice, akin to the use of a stimulant, this might be classed under the honorific, ennobling, and unproductive acts of consumption.

Facebook provides a platform for displays of conspicuous consumption that may possess wider audience reach, and therefore the increased opportunity for receiving validation for such activities. If a person purchases a yacht as a symbol of their pecuniary power, the circle of admirers in the offline world may be small. However, should the same person then post pictures of said yacht, and their cruise in the Caribbean, on Facebook then this may increase personal social capital.

One may note to what end the use of time is put for some users on Facebook in order to increase their reputability. Engaged in the labour of constructing idealized digital facsimiles of the self with a marketizing emphasis on self-as-brand may be performed without any further purpose than abiding by the unwritten norms of the social environment, whereas others who seek to gain some form of tangible capital, there are popular books that instruct Facebook users on how to transform social interactions into pecuniary profit. However, the "all-in" strategy, or "all or nothing" approach to making SNSs the source of actual income may be akin to the goldrush once the speculators had already staked the most lucrative claims.

Ultimately, social capital indexed on the province of the self, or as a collaboration of groups, when conducted on SNSs such as Facebook, serves the interests of actual capital for Facebook and its affiliated advertisers that seek to marketize and profit from mediated social exchange. It is these entities that either play host to, or leverage social data for targeted advertising, that earns monetary profit. Self-service and self-branding activities provide the appearance of autonomy that underpin the fetishistic rhetoric surrounding the "heroic" entrepreneur, if at the very least the individual user is "liberated" from the managerial hierarchy in their own self-determination. And yet, the subordination remains as the user swaps out a "boss" or a rigid hierarchical system that is plainly visible in an institutional and industrial 
logic to a fuzzier and more ubiquitous type now occupied by the owners of the networks. The unacknowledged labour involved in profile management and the temporal investment strategies involved in increasing social capital may simply be a redistribution effect of free labour whereby these activities conducted by a large mass of users ultimately provides benefit for the SNSs that underwrite all attempts at social capital increase, be these successful or not. The parallel case, although more monetarily clear, might be the entrepreneurs who develop apps for Apple or Android platforms: no matter the success of the app, the only cost to these companies is hosting, while the developer provides free labour in the hopes of acquiring profit. Should there be a considerable profit, the host takes a significant cut of the revenue.

\section{Facebook, the Abstract Image, and Social Labour}

It is only the image of the social that governs social relations in SNSs, a newly organized territory by which the dictatorship of the mobile device reveals their authority in a network of flows that make social relations possible. Just as physical architecture can be said to be inherently ideological, so too can software architecture that has as its goal the compression of space: "The society which eliminates geographical distance reproduces distance internally as spectacular separation" (Debord 2000, § 167). In Debord's analysis, the more space and time become compressed into commodity-space and commodity-time, the more the individual is alienated from space and time itself, those becoming foreign. One has only to note how space and time are reconfigured by Facebook in terms of "timelines" where one can record the moment of one's birth (now underwritten by Facebook as a colonization of individual history, its absorption of the individual into its own spectacular enclosure) or in the use of geolocation software that converts space into places, a map of commodity sites where particular products and services can be purchased.

A new abundance arises in the form of social labour, itself a disguised version of commodity time, whereby "the concentrated result of social labour becomes visible and subjugates all reality to appearance, which is now its product" (Debord 2000, § 50). In the spectacle's total occupation of social life, it is the spectacle that reconstitutes itself at every interval of social interaction. The earth, now stitched together in the most abstract form of social relations as mere images in network flows, becomes a global market. Every action or production has its goal in the growth of the spectacle, which is the image of the dominant economy and its motivation to grow for growth's sake. The spectacle itself "is not a collection of images, but a social relation among people, mediated by images" (Debord 2000, §4). This, for Debord, represents the apogee of modern capitalist production, completing the historical process of being to having to appearing (Debord 2000, §17). By representing themselves as leisurely individuals, Facebook users engage in an emulative exercise of reproducing situations that may not accord with offline reality. As the spectacle serves a purpose of maintaining a program of further separation, it does so through an illusory reunification: in this case, all being "equal" in the happy banality of Facebook that speaks in a single voice, that being the univocal expression that justifies the current economic society. And so it is the spectacle itself that grants meaning to every individual user's ideas, feelings, and experiences. This can be observed in the collection fetishism that motivates the taking of pictures of travel and social events that are taken solely for posterity and in service of display on Facebook as a form of conspicuous consumption. For some users, an experience may be considered a non-event unless it is uploaded to Facebook. The intrinsic use-value of the experience is demoted to the exchange-value (Debord 2000, §36) that can be generated for the purposes of social capital. However, it is the false use-value of posting the content on Facebook for gaining validation and approval by others that appears to satisfy a social need. In reality, the representations of experience and the self, now digitized, take on a kind of autonomous reality. In some ways, the Facebook user labours in the service of his or her digital representative.

We might characterize such autonomous images of the self as posted online with an appeal to Goffman's (1969) distinction between expression and communication. For Goffman, expression occurs in simply being present, whereas communication is tied to a message that is made with intention, such as a writing or a vocal message. Although Facebook users are 
not perpetually present, their representations are in the form of the accessible profile page that will continue to express on their behalf. The initial act was one of communication; that is, a user constructed a profile and posted content such as a personal photo and an "about" section. However, once this is complete, it may fall back into simply expression.

The three registers of alienation converges on a single medium whereby the user is alienated from others even in the hyperactive connectivity and information feed that masquerades as being simply social. Moreover, alienation from others occurs when the scene and event of social interaction succumbs to its own commodification and the personal story told through the products of consumption (the subscription to certain services offers the user the opportunity to have what they consume fed into the social loop so that others in the network will be kept apprised of what movie, video game achievement, or product they have just purchased). The second alienation concerns being alienated from a world that becomes saturated with a mediated wall of commodified space: the augmented realities that overlay the senses to rewrite space as corporate places, and thus the GPS alerts its "pilot" of distances to the next Starbucks. Lastly, it is an alienation from the self: it is rather telling that on Facebook a user is not permitted to have a relationship with her or himself. With the demands of communications that privilege and expect speed in response as the standard social communication protocol (the text message must be answered immediately), communication itself dispenses with the quality of contemplation. The nodes of the networks are more neuronal in nature, flashing their stimulus responses.

The technical instruments financed and promoted by capitalism promise the unification of a society. In the case of SNSs and the devices required to access them, there is the frequent equivalence drawn between connection and unity, generally marketed as potential. To connect two individuals is a necessary but not sufficient condition of unity. And yet the promise of unity through conspicuous use of the SNS platform still haunts said digital milieus as a vision of the unified, now globalized, mass or village. However, the very technical instruments themselves perform an act of separation. The technical forces of capitalism, in this case being the alliance of neoliberalism and informationism (Castells 1996; Harvey 2005; Neubauer 2011), are the equipment necessary to roll out the specific techniques of separation and alienation (Debord 2000, §171). Owing to the highly competitive nature of increasing capital in the attention economy, class differences may be more rather than less visible despite the promise of the democratizing and equalizing nature of the social web.

The false and spectacular unity afforded by Facebook allows for the trafficking of social value as homogenized units, while at the same time inscribing the users' new relationship to space and time as an abstract image of the spectacular society where commodities reign. These homogenized units of approbation, such as the thumb-icon, effectively represent a sign or token of social worth. Or, to quote Veblen,

to sustain one's dignity - and to sustain one's self-respect - under the eyes of people who are not socially one's immediate neighbours, it is necessary to display the token of economic worth, which practically coincides pretty closely with economic success (Veblen 1919, 67).

The unity is indeed built on separation, and can be pithily expressed: "the spectacle is nothing more than an image of happy unification surrounded by desolation and fear at the tranquil centre of misery" (Debord 2000, § 63).

If social capital, however construed, is a formal cause, its final cause is desire, the material cause is nature in the form of the devices and networks, and the efficient cause that realizes the telos of the capital is labour. What interests us most about Huitton's application of Aristotelian causes to the economic process of social capital is precisely the labour involved. Desire, on the other hand, is the "goal" of social capital insofar as the individual or group seeks gratification according to the demands of desire as a motivational force. That desire may be satisfied by achieving a certain level of status.

Social labour is measured by the objective value of time just as economic capital can be measured as accumulated labour time. As Veblen recognized, the upper classes found me- 
nial labour ignoble, and thus preferred unproductive uses of their time as a mark of their status. If Facebook is cast as a leisure activity, it would then fall under the domain of unproductive time; however, the actual labour being performed does benefit Facebook and its affiliated advertisers, and the quantity of time expended checking Facebook, posting new content, and managing one's profile does suggest it is not exactly leisure. As Debord tells us: "All the consumable time of modern society comes to be treated as a raw material for varied new products which impose themselves on the market as uses of socially organized time." (Debord $2000, \S 151)$. When time, even what can vaguely be considered unproductive, is committed to Facebook, we might ask if the temporal resources being consumed are not ultimately in the service of Facebook and its affiliated advertisers.

The alienated labour of social capital occurs in the wageless space of self-development writ digitally, much of it contrived for a market audience of other entrepreneurs of the digital self. ${ }^{4}$ The user, in conducting labour under the auspices of social entertainment, never truly owns the manicured profile or the digital self-portrait as much as "rents" a space in which it can occupy. Nor does the user own the representation directly for it is the alienated product of the projected ego ideal that can never be fully integrated in the actual self. The only time ownership of profile is assured may be if there is a question of legality whereby the user is legally responsible for some action performed on the SNS. The lack of actual ownership is replaced by a kind of rent, and yet neoliberalism's devolution of risk in the form of extreme responsibilization of subjects assigns all the duties of ownership without the benefits. The user performs his or her labour only ostensibly for the self, but the online self is little more than an accessory and an access point for the advertising narrative and the appearance of enjoyment that is essential for Facebook to promote itself. Facebook has true ownership of the tools and the space in which social interactivity occurs, and it is contingent upon its subscribers to supply their own content and generate the appearance of enjoyment that indirectly performs the function of advertising Facebook to others whilst also maintaining the belief in its social value in the form of constructed communities.

Just as industrial capitalist production fragmented the life-world of the worker, informational-capitalism abetted by neoliberalism fragments the social-world of the (prod)user in a new regime of compressed and discrete time as actual fragments in the form of the tweet, the status update, the addition of a "like." Social time becomes commodified as discrete intervals of quantized social value. The production is no longer indexed on goods, but on the capitalized subject whose digital representative must maximize positive attention as expressed through quantifiable measures.

The stated advantages of a decentralized entrepreneurial model of content production and consumption via sharing and collaboration does not result in a return to the pre-industrial practices of craft production. Instead, the system of desire in economic expansion as a quantitative one simply fragments labour which is still under the domination of the big telecom hosts. Whereas the shift "transformed human labour into commodity-labour into wage-labour" (Debord 2000, §40), the labour of the entrepreneurial subject is effectively pittance or unwaged labour. This continues to be in the service of the more general economy: "The economy transforms the world, but transforms it only into a world of economy," (Debord 2000, $\S 40)$ to which the now unwaged, entrepreneurial social capitalist continues to serve under the illusion of self-direction, and without institutional supports. This allows Facebook to substantially profit from users seeking to increase their status through production in a hyperactive environment governed by competition: "surplus labor is transformed by relentless technological activity, and the means of virtual production produce abuse value" (Armitage 1999, 3).

In terms of social capital resource management, we might reference the desire for quick returns borne of the phenomenon of instant celebrity status (such as an amusing amateur YouTube video going viral) as a kind of supply chain management writ on the miniaturized scale of the individual. Considering that development and refinement of skills and talents

\footnotetext{
${ }^{4}$ It may be noted that a flood of books for would-be entrepreneurs now jockey for bestselling supremacy alongside diet books and ghostwritten political memoirs.
} 
may take significant time and even monetary resources, these may be considered costly inputs. As supply chain management takes especial care in reducing the costs of inputs while maximizing outputs to secure a larger return on investment that equals profit, for those who seek instant social capital with minimum effort, it may be preferable to seek shortcuts. From a strictly time-based calculation, it will take much longer to master the violin prior to sharing one's virtuousity online than it would to record a cat's head stuck in a toilet with one's cell phone. As supply chain management necessitates improving efficiencies in the flow of goods, and reducing costs along the supply chain, this may mean "cutting corners" in order to deliver value-added goods to the consumer.

And yet, the input value of time may be offset when considering the amount of time possibly required in the constant management and revision of one's profile, if not also in posting "fresh" content to stay relevant in one's networks where there is an abundance of content that increases in proportion to the number of users on that network. Those for whom the expectations of content production are especially acute, possibly as a result of having achieved an unprecedented standard of their share of attention due to a previously posted content, this may induce a feeling of performative pressure to not simply achieve the same measurable amount of attention, but to exceed it. Just as it may prove difficult to adjust to a lower standard of living or income, it may also be true of adjusting to a lower share of attention.

Users self-publish their content, but Facebook's model is mostly a modification on earlier forms of publication. The sale of advertising space that marked traditional print was to a readership: "The profits of publication come from the sale of advertising space" (Veblen 2005,182 ) - but in this case, the producer and the publisher are very distinct, for Facebook is in effect the "publisher" and the producers of content are not "hired" by Facebook and are thus unpaid. It is the users themselves that produce the content that further popularizes Facebook, while Facebook acts as a data broker in selling advertising space that is targeted to the prosumers of content. It was Veblen that acknowledged the priority of advertising space as a source of revenue, and that subscriptions were largely secondary.

On Facebook's highly commodified space, the intrusion of advertising is fairly well known, leading to the kind of "commercial fallout" scenario identified by Lewis Mumford in the advertising pollution of urban spaces. "In the advanced regions, social space is invaded by a continuous superimposition of geological layers of commodities (Debord 2000, §42).

For Baudrillard, the "pornography of circuits and networks" $(1988,22)$ is a component part of his claim that it is no longer an issue of the spectacle or the secret, but that the public and private distinction has vanished, and in its place the double obscenity of needless visibility, transparency, and immediacy which focuses on minutiae at the expense of the dramatic stage. Despite Baudrillard's semi-polemical jeremiad that forecloses the continuation of the Debordian spectacle, not all of Baudrillard's prophecies have come to fruition; the era of illusion is still with us, and full transparency still eludes us with respect to those in power who have the means of controlling our access.

\section{Conclusion}

For Veblen, the ideal for technical knowledge was that it would be held in common, apart from pecuniary interests. He envisioned a great Soviet of engineers (Veblen, 1921). When it comes to the productions and insights of Facebook users, however, this is not held in common per se as the repository is entirely pecuniarily motivated, and to paraphrase ThiryCherques, the price of inclusion in the network entails some form of subordination. In this case, Facebook extracts value from posts and profiles for the purposes of facilitating data matching between itself and paid advertisers for targeted advertising. The shadowy side of Facebook in terms of "theft" might be in the instances of image-scraping or simply plagiarizing the content of a user's post.

Social capital - that which is generated from resources held in common - would have to somehow develop a means of resisting the pecuniary interests of those who are not contributing their own capital to a specific community, and are simply profiting by what is generated. However, for as long as social relations are dominated by the predominantly neoliberal spec- 
tacle, and interactions on the Facebook platform are motivated with a view to enhancing status through conspicuous acts of prosumption in a competitive game, the advantages of social capital would only accrue in small part to the entrepreneurial individual, and in larger part to Facebook.

Mestrovic acknowledges that Veblen "would have pointed out that the Internet is most available in Western nations that exhibit the culture of narcissism he sought to unmask" $(2003,14)$. And, perhaps just as Veblen critiqued fashion and ostentation as status-based activity that aligns with a pronounced form of cultural narcissism, it is likely that he might have viewed certain ego-based behaviours of display on Facebook as falling squarely within the domain of narcissism. The extensive use and reliance on platforms such as Facebook among a growing number of individuals exhibits the extent to which unproductive time is spent in virtual production, and that the competitive aspects reduce social interactions to the exchange value that can be generated from said interactions for personal gain.

Ultimately, games of social capital in the quasi-pecuniary drive to seize a larger share of the attention economy reflect the ideological values of neoliberalism, and are sustained by the totalizing aspects of the spectacle in which Facebook is just one of many SNS platforms is an instrument. Veblen was a caustic critic of capitalism, laden as it is with inefficiencies and irrational behaviour culturally inherited from previous phases of production and consumption that, to him, were largely invariant ${ }^{5}$. On the other hand, Veblen's view of technology, as something technical, could provide efficiency and progress, but would cease to hold these qualities in making a firm alliance with capital. Veblen's verdict on what Facebook means at the social and even institutional level can be inferred from these views on the irrational drive for status-aggrandizement.

\section{References}

Anderson, Chris. 2004. The Long Tail. Wired 12.10.http://www.wired.com/wired/archive/12.10/tail.html Armitage, John. 1999. Resisting the Neoliberal Discourse of Technology. cTheory 3 Jan. 1999 Web. 9 Sept. 2013.

Bataille, Georges. 1991. The Accursed Share v. 1. Trans. Robert Hurley. New York: Zone Books.

Baudrillard, Jean. 1988. The Ecstasy of Communication. Trans. Bernard and Caroline Schutze. New York: Semiotext(e).

Baudrillard, Jean. 1993. Symbolic Exchange and Death. Trans. Iain Hamilton Grant. London: Sage Publications.

Bauman, Zygmunt. 1988. Freedom. Minneapolis: University of Minnesota Press.

Benkler, Yochai. 2006. The Wealth of Networks: How Social Production Transforms Markets and Freedom. New Haven: Yale University Press.

Boltanski, Luc and Eve Chiapello. 2005. The New Spirit of Capitalism. International Journal of Politics, Culture and Society 18 (3): 161-188.

Bourdieu, Pierre and Loïc Wacquant. 1992. An Invitation to Reflexive Sociology. Chicago: University of Chicago Press.

Bruns, Axel. 2009. From Prosumer to Produser: Understanding User-Led Content Creation. Transforming Audiences 2009: 3-4.

Castells, Manuel. The Rise of the Network Society. Oxford: Blackwell, 1996.

De Graaf, Nan Dirk and Hendrik D. Fla. 1988. With a Little Help From My Friends: Social Resources as An Explanation of Occupational Status and Income in West Germany, the Netherlands, and the United States. Social Forces 67 (2): 453-472.

Debord, Guy. 2000. [1967]. Society of the Spectacle. Detroit: Black \& Red.

Deleuze, Gilles.1995. Negotiations: 1972-1990. Trans. Martin Joughin. New York: Columbia University Press.

Dyer-Witheford, Nick. 1999. Cyber-Marx: Cycles and Circuits of Struggle in High Tech Capitalism. Chicago: University of Chicago Press.

\footnotetext{
${ }^{5}$ Future work may focus on drawing considerably from the work of Sombart, but also demonstrate the areas of conceptual overlap between Veblen's notion of conspicuous consumption and Boltanski and Chiapello's "third spirit" of capital as fundamentally a "new" model of work that brings together much of the neoliberal apparatus with network-based exploitation.
} 
Ellison, Nicole.B., Charles Steinfield and Cliff Lampe. 2007. The Benefits of Facebook "Friends:" Social Capital and College Students' use of online social network sites. Journal of ComputerMediated Communication 12 (4): 1143-1168.

Fuchs, Christian. 2010. Labor in Informational Capitalism and on the Internet. The Information Society 26 (3): 179-196.

Goffman, Eric. 1969. Strategic Interaction. Philadelphia: University of Pennsylvania Press.

Hardt, Michael and Antonio Negri. 2000. Empire. Cambridge: Harvard University Press.

Harvey, David. 2005. A Brief History of Neoliberalism. Oxford: Oxford University Press,

Huang, Jen-Hung and Yi-Fen Chen. 2006. Herding in Online Product Choice. Psychology \& Marketing 23 (5): 413-28.

Knack, Stephen and Philip Keefer. 1997. Does Social Capital Have an Economic Payoff: A CrossCountry Investigation. The Quarterly Journal of Economics 112 (4): 1251-1288.

Labonte, Ronald. 2008. Social Capital and Community Development: Practitioner Emptor. Australian and New Zealand Journal of Public Health 23 (4): 430-433.

Manzerolle, Vincent R. 2014. Technologies of Immediacy / Economies of Attention: Notes on the Commercial Development of Mobile Media and Wireless Connectivity. In The Audience Commodity in a Digital Age, ed. Lee McGuigan and Vincent R. Manzerolle. Peter Lang.

Merton, Robert K. 1968. The Matthew Effect in Science. Science 159 (3810): 56-63.

Mises, Ludwig von. 1963 [1949]. Human Action: A Treatise on Economics. New Haven: Yale University Press.

Neubauer, Robert. 2011. Neoliberalism in the Information Age, or VIce Versa? Global Citizenship, Technology, and Hegemonic Ideology. tripleC 9 (2): 195-230. http://www.triplec.at/index.php/tripleC/article/view/238

Peck, Jamie and Adam Tickell. 2002. Neoliberalizing Space. Antipode 34 (3): 380-404.

Peters, Michael A., Rodrigo Britez and Ergin Bulut. 2009. Cybernetic Capitalism, Informationalism and Cognitive Labour. Geopolitics, History and International Relations 1 (2): 11-40.

Portes, Alejandro. 1998. Social Capital: Its Origins and Applications in Modern Sociology. Annual Review of Sociology 24: 1-24.

Putnam, Robert D. 2000. Bowling Alone: The Collapse and Revival of American Community. New York: Simon and Schuster.

Stjepan Mestrovic. 2003.Thorstein Veblen on Culture and Society. London: Sage Publications.

Ritzer, George and Nathan Jurgenson. 2010. Production, Consumption, Prosumption: The Nature of Capitalism in the Age of the Digital 'Prosumer.' Journal of Consumer Culture 10 (1): 13-36.

Thiry-Cherques, Hermano. 2010. Intranets: A Semiological Analysis. Journal of Information Science 36 (6): 705-718.

Utz, Sonja. 2010). Show Me Your Friends and I Will Tell You What Type of Person You Are: How One's Profile, Number of Friends, and Type of Friends Influence Impression Formation on Social Networking Sites. Journal of Computer-Mediated Communication 15 (2): 314-335.

Veblen, Thorstein. 2010. [1899]. The Theory of the Leisure Class. N.P.: World Library Classics.

Veblen, Thorstein. 2005. [1904]. The Theory of Business Enterprise. New York: Cosimo.

Veblen, Thorstein. 1919. The Place of Science in Modern Civilization. New York: B.W. Huebsch.

Veblen, Thorstein. 1921. The Engineers and the Price System. New York: B.W. Huebsch.

Walther, Joseph B. 1996. Computer-Mediated Communication: Impersonal, Interpersonal, and Hyperpesonal interaction. Communication Research 23 (1): 3-43.

White, J. 2005. The Relationship Between Profiles and Perceived Popularity Online. Paper written for COMM 501. University of Illinois at Chicago.

\section{About the Author}

\section{Kane X. Faucher}

is an assistant professor in the Faculty of Information and Media Studies at Western University who teaches courses on social media and propaganda. He earned his doctorate in Theory and Criticism from Western and has published widely on Borges, Bataille, Deleuze, Celine, and information theory. $\mathrm{He}$ is the author of Metastability and Metastasis: A Deleuzian Approach to Information (Sense Publishers, 2013), and he is currently at work on another book, Datapolitik: Alienation and the Algorithm in the Age of Big Data. He is also a novelist and works in strategic planning for two consultancy firms. 